\title{
La ética en las funciones sustantivas del personal académico de la Universidad Veracruzana
}

\author{
Hákim Krayem, Mónica Rubiette \\ Universidad Veracruzana, México \\ rhakim@uv.mx \\ del Callejo-Canal, Diana Donají \\ Universidad Veracruzana, México \\ ddelcallejo@uv.mx
}

\author{
Fortuno Hernández, Josefa Carolina \\ Universidad Veracruzana, México \\ jfortuno@uv.mx \\ Canal-Martínez, Margarita Edith \\ Universidad Veracruzana, México \\ mcanal@uv.mx
}

Resumen - Un Código de Ética es una carta de principios interna que guía los fines de la universidad y su finalidad es apoyar a la aplicación justa de las normas y estatutos legales de una institución educativa. De allí el objetivo de este artículo para identificar si los principios del Código de Ética de la Universidad Veracruzana, como referente formal de la conducta y carácter profesional de quienes la integran, se hace presente en la normatividad que rige las funciones sustantivas del personal académico, para otorgarle integridad y confianza a la institución como formadora de estudiantes que se desarrollarán en el ámbito laboral, social, económico y cultural del país con responsabilidad social y ética. Encontramos congruencias importantes y algunos vacíos respecto de las sanciones ante conductas no éticas que se pueden presentar y que pudieran ser un obstáculo en el cumplimiento de la razón de ser de la universidad.

Palabras clave - Código de Ética; responsabilidad social universitaria; normativa universitaria; personal académico;

Abstract - A Code of Ethics is an internal charter of principles that guides the purposes of the university and aims to help the fair application of the legal norms and statutes of an educational institution. Hence, the objective of this article to identify if the principles of the Code of Ethics of the

Interconectando Saberes, 2021

ISSN: 2448-8704

(c) EY-NC-ND
Universidad Veracruzana, as a formal reference of the conduct and professional character of those who make it up, are present in the regulations that govern the functions of academic staff, to grant them integrity and trust in the institution as a trainer of students who will develop in the labor, social, economic and cultural environment of the country with social and ethical responsibility. We found important congruences and some gaps in terms of specifying sanctions for unethical conduct that may occur and that could be an obstacle in the fulfillment of the university's reason for being.

Keywords - Code of Ethics; university social responsibility; university regulations; academic staff;

\section{INTRODUCCIÓN}

La Universidad Veracruzana (UV) inició su existencia formal el 11 de septiembre de 1944, como una institución pública de Educación Superior (IES) respaldada moral y económicamente por el gobierno del estado de Veracruz (UV, 1944-1954). En poco más de siete décadas ha logrado posicionarse en la sociedad al desarrollar una tradición preponderante de carácter humanista, Fecha de Recepción: 23 de septiembre de 2020 Fecha de Aceptación: 18 de enero de 2021 Fecha de Publicación: 31 de enero de 2021 
prevaleciendo sus valores de justicia social, lo que ha beneficiado a la educación y la cultura en el ámbito regional, nacional e internacional.

Las funciones que la caracterizan son la docencia, la investigación, la creación y difusión de la cultura, así como la extensión de los servicios universitarios. Todas esas acciones se cumplen con calidad, pertinencia, equidad, compromiso ético, vocación democrática, vinculadas con los diferentes sectores sociales, en permanente generación y distribución de conocimientos para el desarrollo equitativo y sostenible de su entorno (Valdés, 2008).

Además, cabe resaltar que la UV se plantea como cometido sustancial vivir bajo una ética vinculada con la sociedad para el desarrollo del estado de Veracruz, con la singularidad de la Responsabilidad Social Universitaria (RSU, 2019d), tal y como lo declara en su razón de ser o Misión actual (UV, 2017):

La Universidad Veracruzana es una institución de educación superior, pública y autónoma, que desarrolla sus funciones de docencia, investigación, difusión y creación de la cultura y extensión de los servicios universitarios en las diversas áreas del conocimiento en la ciencia y tecnología, el humanismo, las artes y la cultura con calidad, pertinencia, equidad, ética y en vinculación permanente con los diferentes sectores sociales para incidir en el desarrollo social del estado de Veracruz. Para ello realiza

\footnotetext{
1 Entendidos como las normas generales de comportamiento que orientarán las decisiones y las acciones de los miembros de la Comunidad de la Universidad Veracruzana (Manual de RSU de la Universidad Veracruzana, 2015 p.6).
}

sus actividades con responsabilidad social, compromiso en la transparencia y rendición de cuentas; con políticas de desarrollo sustentable que contribuyan al logro de una sociedad más productiva, justa y segura.

Catapultada por esta razón de ser, la UV anhela para su futuro, conservar su liderazgo en la educación superior sustentada en el respeto y la responsabilidad, es decir, guiada siempre por el faro de la ética. Por ello su Visión para el año 2030 (UV, 2017) es la siguiente:

La Universidad Veracruzana es una institución líder de educación superior, con presencia regional, nacional e internacional, socialmente responsable, innovadora, intercultural e incluyente, con visión sistémica y compleja, que contribuye al desarrollo sustentable, que se distingue por sus aportes en la transferencia de la ciencia y la tecnología, el respeto y la promoción de la cultura; así como por la vinculación efectiva con los sectores social y productivo; con una gestión eficiente y eficaz al servicio de la academia, conformando una institución que promueve los comportamientos éticos, los derechos humanos, el arte y la creatividad, la salud integral, la equidad de género y el respecto a la diversidad cultural, para la formación de ciudadanos éticos y competentes en el ámbito local y global.

De manera particular, los valores y principios ${ }^{1}$ que se encuentran el Programa de Trabajo Estratégico (PTE) 2017-2021 de la UV y que se promueven para un comportamiento ético ${ }^{2}$ son: Dignidad,

${ }^{2}$ Con comportamiento ético se refiere al compromiso individual y colectivo para alcanzar el bien común. Es uno de los principios de correcta o buena conducta aceptados en el contexto institucional y que es afín con 
Igualdad y no discriminación, Libertad, Responsabilidad, Solidaridad, Democracia, Respeto, Seguridad y Cuidado; Honestidad, Integridad, Imparcialidad, Objetividad, Independencia, Transparencia, Rendición de Cuentas y Equidad (UV, 2018).

Lo anterior da cuenta de la identidad de la UV, cuyo fundamento es la ética para hacer realidad sus principios, valores y compromiso moral, así como para llevar a cabo sus cambios y transformaciones -educación para la convivencia, para la democracia y para el desarrollo- y la de todos quienes conforman su comunidad: estudiantes, docentes, investigadores y personal administrativo y manual; en un ambiente de justica, respeto y responsabilidad social. Es así como, en el año 2016 se aprobó el Código de Ética (UV, 2016) como un documento orientador de las normas jurídicas que ya gobernaban a la UV desde sus inicios. En dicho código, se establece el actuar de todos sus integrantes, su comportamiento moral y el carácter institucional que la distingue como una Alma Mater.

El Código de Ética supone una normativa interna de cumplimiento obligatorio, tiene como función fundamentar la aplicación justa de las normas y estatutos legales redactados por los responsables institucionales universitarios, pero en sí mismo no es punitivo desde el punto de vista jurídico, sólo promueve la autorregulación (Fortuno y Hákim, 2019).
Por lo anterior, este trabajo tiene como objetivo identificar si los principios del Código de Ética de la UV, como referente formal e institucional de la conducta personal y profesional de quienes la integran, está presente en la normatividad que rige las funciones académicas de sus profesores e investigadores- Estatuto del Personal Académico-, para otorgarle integridad y confianza a la institución como formadora de estudiantes que se desarrollarán en el ámbito laboral, social, económico y cultural del país con responsabilidad social y ética.

El presente trabajo se estructura en las siguientes partes: en la primera, se expone la importancia de la Ética y la responsabilidad social universitaria, en la segunda, se detalla lo que declara el Código de Ética de la UV y del Estatuto del Personal Académico, así como su estructura y relación con las Obligaciones, Derechos y Sanciones en lo relativo a las conductas éticas; en el tercer apartado se exponen los hallazgos encontrados en el análisis de dichos documentos oficiales; y finalmente, las conclusiones.

\section{RESPONSABILIDAD SOCIAL ÉTICA UNIVERSITARIA}

La responsabilidad social ética en las universidades de Latinoamérica se viene forjando desde el siglo pasado; se trata de una nueva política o modelo de gestión para responder a los 
impactos organizacionales y académicos de las universidades; se distingue tanto de la tradicional extensión solidaria como de un mero compromiso unilateral declarativo y obliga a cada universidad a poner en tela de juicio sus presupuestos epistémicos y su currículo oculto (Valleys, 2014), esto da pauta para reflexionar sobre su carácter y conducta ante la sociedad actual, exigiendo una coherencia institucional de sus integrantes y sus procesos organizacionales curriculares, descubrimientos y socialización del conocimiento, sus líneas de investigación, su normatividad.

En palabras de Valleys, "el modelo de responsabilidad social representa la mejor alternativa que tenemos para arraigar la pertinencia y legitimidad académica frente a la crisis del saber científico en la sociedad del riesgo, así como la decadencia de la enseñanza socialmente anclada en la era de las multinacionales universitarias" (2014, p 105). Del impacto en la sociedad contemporánea, nace su importancia y desafío.

\section{La importancia de la Ética universitaria}

Para una institución educativa la Ética es fundamental si es entendida como el "ethos" que significa 'carácter' o 'perteneciente al carácter'. Compartimos la visión de Cortina (2013) cuando afirma que la Ética trata de "la formación del carácter de las personas, de las instituciones y de los pueblos" (p.34). Desde este sentido, consideramos que una institución educativa sí puede tener la libertad para forjarse un 'buen carácter' que le permita: cultivar acciones positivas encaminadas hacia una educación de calidad, tener siempre presente sus virtudes y mantener alejados los vicios, así como permitirse la capacidad de cambiar actuando con justicia en la toma de decisiones con conciencia.

Por lo anterior, y dado que nos referimos al ámbito laboral de los académicos e investigadores, es pertinente ejercer la denominada Ética Profesional, ya que ésta permea en los códigos deontológicos que regulan la actividad profesional de la UV y se conoce como ética normativa porque presenta los principios y reglas de cumplimiento obligatorio, a diferencia del Código de Ética el cual conjunta las directrices morales que deberán seguir los miembros de la comunidad universitaria, más allá del cumplimiento jurídico. Cabe mencionar que los códigos deontológicos no siempre se cumplen, aunque se respeten, debido a la falta de claridad de quién deberá cuidar por su cumplimiento ni cuáles son las sanciones para quienes los vulneren, ni quién deberá imponerlas. Si bien se cuenta con colegios y academias, las normas dictadas en el código deontológico deberán ser pactadas y aprobadas de manera unánime por todos los miembros de la comunidad para la cual se elaboran, en aras de realizar un determinado trabajo de forma correcta, adecuada y eficiente.

Cortina y Oviedo (2008) defienden el carácter de una institución como el modo de ser que va adquiriendo a lo largo de su vida, su conciencia, en especial que sea ética y no sólo moral. Es decir, justa cuando regula las relaciones entre los miembros de su comunidad y no sea sólo un 
conjunto de normas o códigos morales que de manera obligatoria o coercitiva se deba reverenciar, pues no se trata de elaborar una disertación motivacional o espiritualista, sino más bien un documento teórico-conductor que permita la mejor manera de convivir con libertad y honestidad, tal como lo expresa Ferrater, mencionado por Solórzano, "que establezca una conducta a seguir ante los hechos que cotidianamente se presentan" (Solórzano et al., 2019, p. 260).

El último escalón para formar en la educación de la Ética o educar éticamente de manera profesional recae en la universidad. Su importancia para atender lo relativo a la enseñanza y fomento de los valores morales debe nacer de la reflexión sobre sí misma y sobre sus creencias ¿cuál es la importancia de ser ético? ¿por qué es importante ser justo? ¿cuál es la relevancia de ser honesto? ¿por qué es importante ser mejor? ¿qué valores deberán ir primero? Las respuestas que se otorguen conducirán a la institución hacia la coherencia entre el decir y el hacer con perspectiva crítica, y esto formará la base en la que se sustente el carácter y reputación de la educación que la comunidad universitaria guardará en su memoria y nunca olvidará.

Una educación universitaria para el siglo XXI, debe ser aquella que permita la enseñanza, reflexión y ejercicio de los valores considerados más valiosos,

3 Con este término nos referimos a lo que debería permear toda función universitaria, en su diseño, implementación y evaluación: la responsabilidad social, tales como: la libertad tomando en cuenta a los otros, la igualdad, la solidaridad, el respeto mutuo, entre otros más. Aquella que incluya en cada programa -transversalización ${ }^{3}$ en el currículo-, una asignatura de ética tanto para las ciencias como para las humanidades con un sentido altamente intersubjetivo, que permita el diálogo entre profesores y estudiantes. Con ello se alcanzará el fin último de las IES: formar profesionales convencidos de que una visión integral y sentido ético les otorgarán los argumentos para reflexionar, dialogar y deliberar cualquier cuestionamiento que venga de las emociones, los dogmas, o la intuición.

Esto último requerirá de profesores, investigadores, y autoridades totalmente convencidos de que deben actuar cooperativamente por un mismo bien común y hacerlo efectivo (Colby, et al., 2003) y esto debe hacerse para buscar la verdad más allá de las barreras de clase, género y nacionalidad, respetar $\mathrm{y}$ tolerar activamente la diversidad $\mathrm{y}$ humanidad de otros (Nussbaum, 2005), por ello la importancia de que el comportamiento de todos se alinee a las leyes, reglamentos y disposiciones particulares de la institución educativa.

Para que la educación universitaria sea íntegra, deberá incluir además de la formación de los estudiantes y actualización de sus profesores, una relación virtuosa y responsable con los recursos económicos que recibe de la sociedad, con los recursos humanos que forma y con las acciones

pero desde un enfoque multidisciplinar (Manual de RSU de la Universidad Veracruzana, 2015). 
que realiza con ella. Por ello es relevante el concepto de la responsabilidad social, que deberá asumirse inevitablemente desde la ética que sustente la institución, de forma auténtica, alejada de cumplimientos burocráticos, para impulsar su cambio y que este sea realmente transformador para que su impacto sea de calidad y pertinencia en la sociedad de la que forma parte.

\section{Responsabilidad Social Universitaria}

Para dar un paso hacia los valores éticos universitarios, en 2012 la Asociación Nacional de Universidades e Instituciones de Educación Superior (ANUIES) consideró importante apoyar el concepto de Responsabilidad Social (RS) en las Institituciones de Educación Superior (IES), considerándola como un nuevo valor y principio rector que debería permear de manera transversal a todas las funciones sustantivas de dichas instituciones educativas (ANUIES, 2012).

Aun cuando no existe una definición consensuada de RS, la ANUIES la define como:

La operación de una política de gestión académico-administrativa, definida por cada institución en el marco de su misión, sus principios y valores, para llevar a cabo con calidad y pertinencia sus funciones, orientada al logro de resultados socialmente significativos mediante los cuales busca contribuir al desarrollo integral y sustentable de su entorno y participar en la construcción de una sociedad más próspera, democrática y justa. (ANUIES, 2018 p. 80)
Es así como desde el año 2015, y en julio del 2019, la UV ha venido conformando su concepto de RSU, el cual se mantiene en construcción, pero la versión actual es la siguiente:

Es el compromiso de la universidad para difundir y poner en práctica una serie de conocimientos y valores en la formación profesional, en los procesos de investigación, gestión y extensión, funciones que deben estar enfocadas a la solución de problemas sociales mediante cuatro procesos: Gestión ética y sustentable de la universidad, formación de ciudadanos conscientes y comprometidos, generación y difusión de conocimientos socialmente pertinentes, y participación social para un desarrollo más equitativo y sostenible. (UV, 2019d, p. 20)

De ahí que sea un compromiso social el que las IES aseguren que sus funciones se realicen bajo una ética universitaria, con pertinencia, equidad, pluralidad, paz, justicia, honestidad y calidad, buscando la generación de condiciones y ambientes en pro del desarrollo y realización de toda su comunidad académica y por ende beneficiar a la sociedad. Por ello, De la Isla (2004) le asigna un valor a la ética universitaria, al papel de mostrar los medios y elementos más convenientes y debidos para la construcción de ese ambiente y el cumplimiento de sus fines.

La ética universitaria tiene que ser aquella que se amalgame a la responsabilidad social. Desde su nacimiento, durante los años veinte y su fortalecimiento durante los años cincuenta con las éticas aplicadas, el concepto de responsabilidad social se ha venido ampliando y reconociendo su 
rentabilidad para todas aquellas empresas que lo apliquen (Organización Internacional de Normalización (ISO, por sus siglas en inglés,) 26000), que lo integren como una buena práctica ya que genera confianza, buena reputación, prestigio, y sus productos tienen un factor de innovación, es decir los respalda una garantía genuina. Así, las universidades no serán sólo formadoras de estudiantes, sino de profesionales bien educados, individuos respetuosos de su cultura, con valores intangibles pero reconocibles, que den cuenta de la relación simbiótica entre la universidad como organización y los seres que la conforman.

La ética de una universidad socialmente responsable es aquella que busca la justicia, el interés de todos y no solo de un grupo, la que se responsabiliza siempre por las consecuencias al momento de tomar sus decisiones, por ello sus principios y valores están en congruencia con lo establecido en los documentos regulatorios y legales; se trata de ser responsables éticamente y no transgredir a la institución que nos acoge, ni a los estudiantes a los que nos debemos ni a la comunidad (Ladriere, 2000).

En el 2001, la Unión Europea presentó el "libro verde" (Comisión de las Comunidades Europeas (CCE), 2001), donde caracteriza a la RS corporativa como la integración voluntaria, por parte de las empresas, de las preocupaciones sociales y medioambientales en sus operaciones comerciales y en sus relaciones con sus interlocutores. Allí proponen convertir a la economía europea, basada en el conocimiento, en la más competitiva y dinámica del mundo capaz de crecer económicamente de manera sostenible con más y mejores fuerzas y con mejor cohesión social. Se considera que el mercado es necesario, pero no suficiente, es importante hacer rentable la economía, pero asumiendo la responsabilidad social. Las razones que sostienen son: a) cada vez más la sociedad exige que las empresas y las universidades sean éticas, ya que manejan recursos sociales, y porque su actividad tiene influencia e impacto social; b) la presión de los mercados de trabajo reclama mayor calidad de los profesionistas y lo relacionan con los índices de posicionamiento de las universidades, la mejor gestionada; y, c) si bien la RS se asume voluntariamente, cada vez más los gobiernos y estados elaboran leyes y sugerencias que pueden obligar a las instituciones a cumplir con esos deberes, a demandar que no se engañe y que expresen claramente lo que van a hacer, que presenten públicamente sus trabajos con la comunidad a través de memorias de RS.

\section{CÓDIGO DE ÉTICA Y ESTATUTO DEL Personal ACADÉMICO DE LA UNIVERSIDAD VERACRUZANA}

Para lograr el objetivo de este artículo, se analizaron los documentos normativos del personal académico, dedicado a las funciones de docencia e investigación, que requieren de una ética aplicada que les sirva de guía para un rumbo seguro y socialmente aceptado por el entorno. Los académicos deben ser capaces de prever las consecuencias de sus acciones, tener la capacidad 
de formular juicios de valor sobre sus acciones y la de los otros (Ayala, 1991), de conocer sus derechos y tener conciencia del alcance de cada uno de sus comportamientos y estos últimos, se perfilan en el Código de Ética de la UV.

\section{Código de Ética de la UV}

El Código de Ética de la UV es una carta de principios que guía los fines de la universidad, desde la perspectiva ética y bajo un estilo declarativo; en este documento se identifican un conjunto de buenas prácticas y conductas que deben servir de referente en la convivencia y quehacer cotidiano dentro de la institución, pero no se le considera como un conjunto de normas a partir de cuyo incumplimiento surja un proceso sancionador (2016).

A continuación, se presentan de manera sucinta, los principios y valores, así como una breve descripción de cada uno de ellos, que integran el Código de Ética de la UV (2016):

a) Dignidad, igualdad y no discriminación: reconocimiento de que todas las personas son valiosas y merecen respeto, haciendo énfasis en que en ninguna circunstancia deben ser tratadas como objetos o medio para conseguir algún fin; además, expresa la prohibición absoluta de todo tipo de discriminación, sea por acción u omisión.

b) Libertad y responsabilidad: refiere a la capacidad de autodeterminación de las personas que no tiene más límite que los derechos de terceros, así como la conducta responsable de cumplir de forma diligente con todos los deberes/obligaciones que nos son exigibles en virtud de las funciones que realizamos como miembros de la institución.

c) Solidaridad: comprende la relación recíproca o de interdependencia entre los miembros, ya sea en momentos difíciles o situaciones que requieran apoyo; implica un sentimiento de unidad en busca de lograr las metas o intereses comunes.

d) Democracia: forma de organización social en un marco de protección de las libertades y de los derechos humanos de todos, así como de la búsqueda del mejoramiento constante de las condiciones económicas, sociales y culturales de las personas.

e) Respeto: reconocimiento de la dignidad humana y respeto a la diversidad sexual, cultural, generacional, étnica, lingüística, de género y de pensamiento, entre otras, como riqueza para el ser humano.

f) Seguridad y cuidado: entendida como la promoción del respeto y la protección de los derechos humanos con libertad, dignidad y en igualdad de oportunidades, tanto en lo personal como en las relaciones con los otros, con el propósito de hacer bien las tareas encomendadas, asistiendo a otros cuando sea necesario.

g) Honestidad e integridad: implica un comportamiento recto, probo y honrado, siendo íntegro al no apropiarse del esfuerzo, mérito o trabajo de otras personas o de todo aquello que no le pertenezca. Supone, además, ser congruente entre los pensamientos, sentimientos y acciones, sin afectar los derechos de otras personas. 
h) Imparcialidad, objetividad e independencia: implica mantener estricta distancia de las partes en un conflicto para que ninguna de ellas influya en alguna decisión y éstas deben adoptarse en un marco de la legislación y normativa aplicable, sin presión o interés alguno, separando los sentimientos y formas de pensar personales.

i) Transparencia y rendición de cuentas: cualidad tanto personal como institucional que implica actuar sin ocultamientos, sin doble sentido o con intereses ocultos, haciendo también pública la información relativa al funcionamiento, procedimientos internos, la administración de los recursos (humanos, materiales y financieros), los criterios con los que asumen las decisiones, etcétera.

j) Equidad: principio ético que busca la justicia en la igualdad entre los miembros de la comunidad universitaria, reconociendo las diferencias individuales.

En la parte final, el Código de Ética declara que en un futuro estos principios serán incorporados tanto en los programas como en las experiencias educativas para fortalecer el eje axiológico del Modelo Educativo vigente de la UV y que su aceptación sea explícita en las competencias de los egresados.

\section{Estatuto del Personal Académico de la Universidad Veracruzana}

De los documentos regulatorios: Ley Orgánica (2019c) y Estatuto General (2019a), emana el Estatuto del Personal Académico (2019b) de la UV. Dado que dichos documentos regulatorios enuncian los fines, valores y principios que cobijan las atribuciones de la Universidad Veracruzana, se presenta a continuación, el escrutinio que se realizó en ambos documentos desde la ética.

La Ley Orgánica de la Universidad Veracruzana (1996), en sus artículos 2 y 3, menciona que los fines a perseguir de la educación superior son los de:

... conservar, crear y transmitir la cultura, en beneficio de la sociedad y con el más alto nivel de calidad académica; a través de la docencia, la investigación, la difusión de la cultura y extensión de los servicios, para con ello poder incidir en la solución de problemas y en el planteamiento de alternativas para el desarrollo (p.13).

Así mismo, en la misma ley, en el artículo 11, se establece que una de sus atribuciones es "...impulsar en sus programas académicos, los principios, valores y prácticas de la democracia, la justicia, la libertad, la igualdad, la solidaridad y el respeto a la dignidad humana" (p.15).

La relación que esta ley, actualmente tiene con el Código de Ética de la UV es sólo enunciativa, porque sólo espera [subrayado nuestro] que algunos de los principios éticos se incorporen en el desarrollo curricular de los Programas Educativos. 
El Estatuto General, es de observancia común y obligatoria para todos los integrantes de la institución, y tiene como objetivo establecer las normas generales para la organización y funcionamiento interno, le corresponde al Consejo Universitario General su aprobación y modificación. Además, dicho Estatuto fortalece los atributos de la autonomía universitaria garantizando el ejercicio del quehacer académico y administrativo con coherencia, flexibilidad y dinamismo (Estatuto General, 2018) de este se derivan los demás estatutos universitarios particulares que sientan las bases sobre el funcionamiento de la Universidad.

\section{El Estatuto del Personal Académico vigente,} presenta el conjunto de normas de la relación entre la universidad y el personal académico, con la finalidad de generar un equilibrio para el correcto funcionamiento. En el apartado inicial, de exposición de motivos (2019b, p.5) declara que: “...necesita continuar la adecuación de todas las normas que integran su marco jurídico para regular [subrayado nuestro] las relaciones existentes entre todos sus integrantes”. Y continúa “...Con este estatuto se pretende ahora regular [subrayado nuestro] las estructuras y relaciones actuales para estar en capacidad de resolver la problemática real de la Universidad y responder a las nuevas circunstancias". Hemos subrayado el verbo regular porque, hasta la reforma aprobada por el Consejo Universitario (2019e) celebrada el 9 de diciembre del 2019, esta regulación todavía no considera en su accionar escrito a la ética, a pesar de la existencia del Código y de la Responsabilidad Social.
El marco jurídico del Estatuto (2019b) sólo define y establece las reglas precisas del personal académico: de su clasificación, de su ingreso, promoción y permanencia, de las reglas de promoción y desarrollo, del programa general de estímulos, de la productividad y de todos los productos que van a evaluarse para los programas de premios. También declara las atribuciones, los derechos y obligaciones, así como las faltas y sanciones (Estatuto del personal académico de la UV, 2018).

Consideramos que violentar alguna de las normas universitarias prescritas - que regulan, ordenan y establecen el funcionamiento de la institución educativa y van ligadas a sus políticas académicas y científicas- por parte del personal académico, de autoridades 0 de cualquier miembro de la universidad, significa faltar a nuestras "obligaciones", pero también, el incumplimiento a uno de nuestros "derechos", representa una transgresión a nuestra integridad y dignidad.

Ante tales posibles faltas, consideramos relevante revisar e identificar lo declarado en el Estatuto del Personal Académico 2018 en congruencia con los principios y valores establecidos en el Código de Ética de la UV para identificar los efectos o consecuencias en los casos en que se presenten comportamientos no éticos. 
En su último Título XVII, de los Capítulos I al IV, en específico en lo referente a sus Derechos, se describen un conjunto de prerrogativas como son: los estímulos, participaciones en los órganos colegiados de autoridad universitaria; ocupar puestos de autoridad académica o funcionario universitario, disfrutar del año sabático, obtener becas para estudios de posgrado, entre otros igual de importantes.

A su vez, se identifican también en este Título, las Obligaciones Generales y las específicas dependiendo de su tipo de contratación y función: Académico, Técnico Académico o Ejecutante en funciones de docencia, de investigación y de extensión detallándose las actividades en las que, de manera precisa, deben participar: las Juntas Académicas, desempeñar las comisiones que se le encomienden, presentación de informes sobre sus actividades, participación en los Programas de trabajo de su entidad académica de adscripción, cumplir la carga docente puntualmente, abstenerse de impartir clases particulares con remuneración, participar en todas las representaciones y giras que se programen, entre otros y según sea el tipo de contratación.

Por último, en dicho estatuto, se describen en los artículos 201 y 202, las Faltas y Sanciones enunciando que:

El incumplimiento de las Obligaciones establecidas y las específicas derivadas de la carga académica, como son la deficiencia en las labores académicas, el uso inadecuado de parte o todo el patrimonio universitario, acciones que atenten contra la vida universitaria (sin especificar cuáles), faltas de respeto entre los integrantes de la comunidad y alterar o falsificar documentos oficiales, tendrán cuatro tipos de sanciones: amonestación, extrañamiento escrito, suspensión temporal hasta por ocho días o rescisión, si las faltas son reiteradas o de tal manera graves que afecten a la vida académica de la institución; lo anterior determinado por un procedimiento específico descrito en dicho estatuto (Estatuto del Personal Académico, 2018, p. 39).

\section{HALLAZGOS}

En la revisión realizada a los documentos normativos se encontraron evidencias declaradas sobre comportamientos no éticos, así como el establecimiento de sanciones cuando se trate del programa de estímulos al desempeño académico, tales como:

Plagio de textos, presentación de documentos probatorios falsos 0 alterados, emisión de un aval o juicio o dictamen en su propio beneficio, actuación académica que denote ventaja de oportunidad en la participación por auto designación en situaciones tales como jurado de exámenes de oposición y profesionales, pre jurado, arbitraje, asesorías o participación en actividades 0 programas de vinculación (Estatuto del Personal Académico, 2018, Art, 140, pp.34-35 y Estatuto del Personal Académico, 2019b, Art, 140, pp.35).

Conductas no esperadas que son enunciadas en los principios y valores referidos en el Código de ética, lo que denota una congruencia en ambos documentos. 
Se explicita también procedimientos que dan transparencia a determinados procesos, como premio al decano, otorgamiento de recategorización, convocatorias de plazas, entre otros, que revelan que se alude a Principios como la igualdad, transparencia y rendición de cuentas, imparcialidad, objetividad, sin que se explicite que se trata de los principios éticos declarados en el Código de Ética.

En lo relacionado al apartado de Derechos y Obligaciones que enuncia el estatuto (2018, $2019 b)$, se identifica también una congruencia con el principio de Responsabilidad del Código de Ética de la UV al mencionar que se debe cumplir de forma diligente con todos los deberes que son exigibles en virtud de las funciones que se realizan y el tipo de contratación que se tenga, de conformidad con la normatividad universitaria y en busca de que las prácticas académicas conduzcan a la excelencia académica; sin embargo, tampoco hace alusión al Código de Ética, a pesar de que este se elaboró en el 2016.

Por otro lado, el estatuto redirige su lectura a una Reforma del Estatuto general (2015), en donde se agregan funciones al Abogado General, a la Dirección de Asuntos Jurídicos, Dirección de Normatividad para revisar inconformidades o faltas cometidas por los miembros de la comunidad universitaria. Se agrega además que la Coordinación de la Unidad de Género asesore, remita, acompañe y de seguimiento de los casos por hostigamiento u acoso sexual, discriminación por sexo o género o cualquier tipo de violencia cometida hacia quienes integran la comunidad universitaria (Principios éticos de Equidad y Respeto) (Reformas al Estatuto General, 2015).

En ese mismo documento, se fundamenta sobre el ingreso, destino y aplicación de las cuotas voluntarias que se reciben en las entidades académicas (Principio de Transparencia y Rendición de Cuentas). Así mismo, se establece la dependencia responsable del seguimiento y control de los bienes muebles, inmuebles y derechos patrimoniales de la UV -principios éticos de Responsabilidad, Transparencia, Honestidad(Reformas al Estatuto General, 2015), sin referenciarlo al Código de Ética.

Respecto a las Obligaciones, Faltas y Sanciones, el Estatuto General en su artículo 336, frac. VI, dice lo siguiente:

Las autoridades unipersonales, funcionarios y toda persona que desempeñe un empleo, cargo o comisión con atribuciones de mando o manejen o apliquen recursos económicos de la Universidad Veracruzana tendrán, entre otras obligaciones:

Excusarse de intervenir en cualquier forma en la atención, tramitación o resolución de asuntos en los que tenga interés personal, familiar o de negocios, incluyendo aquellos en los que pueda resultar algún beneficio para él, su conyugue o parientes consanguíneos hasta el cuarto grado o por afinidad o para terceros con los que tenga relaciones profesionales, laborales 0 de negocios o para socios o sociedades de las que la autoridad o funcionario o las personas antes referidas formen $o$ hayan formado parte. Principios éticos de Objetividad, Honestidad, 
Responsabilidad, Imparcialidad- (Estatuto General, 2015, Art. 336, frac. VI, p. 132).

No obstante, identificamos que existen comportamientos explícitamente declarados en el Código de Ética que no están establecidos como obligaciones/derechos del personal académico y mucho menos se establece la ordenanza o sanción para los casos, por mencionar algunos: maltrato físico, psicológico o trato discriminatorio a cualquier alumno; censura ante la libre expresión de ideas o posturas de académicos frente a quienes cuentan con una posición jerárquica o de poder o por contar con mayores grados académicos o reconocimientos, o bien, cuando se condicionan los procesos de evaluación o calificación a personal académico que no está de acuerdo con las posturas de quienes ostentan una posición jerárquica.

Otros comportamientos relevantes enunciados en el Código de Ética, que no se encuentran alineados al Estatuto del Personal Académico, son los siguientes: cuando se ofrecen clases particulares remuneradas o se les solicita a los alumnos acudir a domicilios $u$ oficinas particulares a aplicar algún examen o recibir alguna asesoría; cuando en proyectos de investigación se usan indebidamente muestras biológicas, datos humanos, animales, etcétera; cuando se obstaculizan los logros académicos por diversa índole (creencias o simpatías distintas a las propias); cuando se entrega información falsa, confusa, no verificable o parcial (a excepción del programa de estímulos al desempeño académico); simular procesos editoriales con cargo a los recursos financieros universitarios, alterar datos o inventarlos; distribuir de manera injusta y no equitativa las actividades y los recursos materiales y financieros entre el personal de una entidad; extraviar o alterar algún documento de algún aspirante a ocupar un puesto o un beneficio, entre otros más.

\section{CONCLUSIONES}

La Universidad Veracruzana ha iniciado sus funciones sustantivas como una institución con responsabilidad social y ética con la intención de fortalecer los valores y principios en que se ha sustentado por más de 70 años; prueba de ello es la gestión de su Código de Ética, su Manual de RSU, diversos foros con la participación de la comunidad universitaria en todos sus niveles y de personas del exterior a la institución para conocer la percepción de nuestro propio quehacer, además de ofrecer cursos de capacitación al personal académico, reformas a la normatividad universitaria, entre otros.

Reconocer la necesidad de reflexionar sobre su carácter y conducta resulta relevante en tanto este ejercicio otorga coherencia y congruencia a sus integrantes, a su legislación, a sus procesos y procedimientos, a sus planes y programas educativos, es decir, le proporciona como institución de educación superior, legitimidad académica y respaldo ético, tanto al interior como al exterior. 
Si bien es cierto que en la UV existen también dependencias y protocolos como la Comités de Equidad y Género, la Defensoría de los Derechos Universitarios, la Comisión de Honor y Justicia, La Comisión de Reglamentos, Código de Ética, Manual de Responsabilidad Social, entre otros, se carece aún de un mecanismo de ordenanza clara y sanciones aplicables explicitas en los casos en que se infrinja alguno de los comportamientos éticos expresados en el Código de Ética y que no se mencionan en el Estatuto del Personal Académico, mismos que podrían inhibir la convivencia sana, el bien común de la comunidad universitaria y su credibilidad como institución ante el entorno social.

Esperamos que los hallazgos identificados contribuyan a las funciones de gestión de la ética de la universidad que brinden garantías y significado, así como justicia y legalidad, tanto a los ordenamientos legales ya instituidos, como a las acciones que se realizan de la gestión ética, haciendo transparente y operable el ejercicio académico, la interacción y convivencia con humanismo para buscar la verdad en el entendido estricto de que no se trata de voluntades, sino de desenvolverse con un compromiso moral de cada integrante de la universidad.

Agregamos también que tener claridad en el deber ser y de las consecuencias de lo no aceptable, éticamente hablando, es la mejor forma de democracia y de evitar la injusticia y las grandes brechas entre las personas y los pueblos (Minte y Villalobos, 2006), por ello consideramos que es indispensable que la comunidad académica y administrativa se sume a continuar con el esfuerzo de las autoridades universitarias, para que las tareas se desempeñen bajo las disposiciones éticas, criterios claros, objetivos y confiables para el logro congruente de los objetivos institucionales, partiendo del hecho que los académicos son los formadores y el modelo más cercano de los futuros profesionistas.

Como institución socialmente responsable, la Universidad Veracruzana debe contar con una cultura de valores que permee el quehacer cotidiano y permita la autoregulación, puesto que de acuerdo con Fuentes:

La universidad está llamada, por su nombre mismo, a mediar entre las culturas, desafiando prejuicios, extendiendo nuestros límites, aumentando nuestra capacidad para dar y recibir y nuestra inteligencia para entender lo que nos es ajeno y para que "el silencio no imponga su oscura soberanía» (2002 p.67).

Por lo tanto, las faltas que se llegasen a presentar en la interacción cotidiana, no se conviertan en un obstáculo en el cumplimiento de la razón de ser de la universidad y para que la "confianza y prestigio" que se genere como institución en la sociedad, fortalezca la Ética Profesional de nuestros egresados y de la comunidad académica y administrativa.

Por último, la Universidad Veracruzana debe actuar bajo los preceptos de una Ética institucional con su Código Ético, esto garantizará una convivencia sana y cordial para el bien común de sus miembros y ello se reflejará en un entorno de trabajo 
agradable, traduciéndose en una mayor motivación, productividad y rendimiento eficiente y creativo, lo que repercutirá en una imagen institucional fortalecida que impacte a la sociedad de la que forma parte.

\section{REFERENCIAS}

Asociación Nacional de Universidades e Instituciones de Educación Superior. (2012). Inclusión con responsabilidad social: Elementos de diagnóstico y propuestas para una nueva generación de políticas de educación superior. México. Recuperado de: http://coplan.azc.uam.mx/webdocumentos/si ntesis/inclusionanuies2012.pdf

Asociación Nacional de Universidades e Instituciones de Educación Superior. (2018) Visión y acción 2030. Propuesta de la ANUIES para renovar la educación superior en México. Diseño y concertación de políticas públicas para impulsar el cambio institucional. Recuperado de: https://visionyaccion2030.anuies.mx/Vision accion2030.pdf.

Ayala, F. J. (1991). Origen y evolución del hombre. Alianza Editorial.

Colby, A., Ehrlich, T., Beaumont, E., \& Stephens, J. (2003). Educating Citizens: Preparing American Undergraduates for Lives of Moral and Civic Responsibility. Publisher JosseyBass.

Comisión de las Comunidad Europeas. (2001). Libro Verde. Fomentar un marco europeo para la responsabilidad social de las empresas. Recuperado de: https://eurlex.europa.eu/legalcontent/ES/TXT/PDF/?uri=CELEX:52001DC 0366\&from $=E S$

Cortina, A. (2013). ¿Para qué sirve realmente la Ética? Editorial Paidós.

Cortina A. Y Oviedo N. (2008). Etic of the cordial reason. Educate in citizenship in the 21st century. Akal editorial.

De la Isla, C. (2004). Ética y Universidad. Revista Estudios, № 69, Vol. II, verano, pp. 7-18. Recuperado de: http://estudios.itam.mx/sites/default/files/estu diositammx/files/069/000173271.pdf
Fortuno, J. y Hákim, M. (2019). Código de Ética para las instituciones educativas universitarias. Educación para el desarrollo. Editora del Gobierno del Estado de Veracruz. 1ra. Edición.

Fuentes, C. (2002). En esto creo. Seix Barral. Ladriére, J. (2000). El impacto de la ciencia y la tecnología en la ética. Editorial Nova.

Minte Münzenmayer, A. y Villalobos Clavería, A. (2006). Gestión ética del trabajo pedagógico en el mundo globalizado. Aporte para el enfoque de competencias. Horizontes Educacionales (11). ISSN: 0717-2141. Recuperado de:

https://www.redalyc.org/articulo.oa?id=979/9 7917575002

Nussbaum, M. (2005). El cultivo de la humanidad. Una defensa clásica de la reforma de la educación liberal. Paidós Ibérica.

Organización Internacional de Normalización (ISO), 26000:2010. Guía de Responsabilidad Social. https://www.iso.org/obp/ui\#iso:std:iso:26000: ed-1:v1:es

Solorzano, S., Sánchez, L., Molina, P. (Especial Noviembre, 2019). Concepción de la ética desde la visión de las instituciones de educación superior. Revista Científica Dominio de las Ciencias. Vol. 5, núm. 1. Ecuador. Recuperado de: https://dominiodelasciencias.com/ojs/index.p hp/es/article/view/1042/1529

Universidad Veracruzana. (2015). Reformas al Estatuto General. Recuperado de: https://www.uv.mx/legislacion/files/2016/01/E statuto-General-Reformas.pdf.

Universidad Veracruzana. (2015). Manual de Responsabilidad Social para la Universidad Veracruzana. Recuperado de: https://www.uv.mx/apps/cuo/tallerRSU2/docs /Manual\%20de\%20RS\%20UV.pdf

Universidad Veracruzana. (2016). Código de Ética. Recuperado de:

https://www.uv.mx/legislacion/files/2017/07/ Codigo-de-etica-de-la-UniversidadVeracruzana.pdf

Universidad Veracruzana. (2017). Comisión de Reglamentos. Recuperado de: https://www.uv.mx/legislacion/files/2017/07/ Reglamento-CUG-UniversidadVeracruzana.pdf 
Universidad Veracruzana. (2018). Programa de trabajo estratégico 2017 - 2021 Pertenencia y Pertinencia. Recuperado de: https://www.uv.mx/documentos/files/2019/05 Ipte-2017-2021.pdf

Universidad Veracruzana. (2018). Estatuto del Personal Académico. Recuperado de: https://www.uv.mx/legislacion/files/2018/12/E statutoPersonal-3diciembre2018.pdf

Universidad Veracruzana. (2017). Plan General de Desarrollo 2030. Recuperado de:

https://www.uv.mx/planeacioninstitucional/fil es/2018/04/PGD-2030-y-PTE-2017-2021.pdf

Universidad Veracruzana. (2018). Estatuto General de la Universidad Veracruzana. Recuperado de: https://www.uv.mx/legislacion/files/2018/06/E statuto-General-11062018.pdf

Universidad Veracruzana. (2019c). Estatuto General de la Universidad Veracruzana. Recuperado de:

https://www.uv.mx/legislacion/files/2020/03/E statuto-General-UV-2020.pdf

Universidad Veracruzana. (2019b). Estatuto del Personal Académico. Recuperado de: https://www.uv.mx/legislacion/files/2019/12/E PA-2019.pdf

Universidad Veracruzana. (2019c). Ley Orgánica de la Universidad Veracruzana. Recuperado de:

https://www.uv.mx/legislacion/files/2019/04/L ey-Organica-Universidad-Veracruzanareimpresion2017.pdf

Universidad Veracruzana. (2019d).

Responsabilidad Social Universitaria en la Universidad Veracruzana. Alcances y compromisos mediatos. Recuperado de: https://www.uv.mx/rsu/files/2019/11/RSU Po litica institucional-UV.pdf

Universidad Veracruzana. (2019e) Reformas al Estatuto del Personal Académico.

Recuperado de:

https://www.uv.mx/legislacion/files/2020/01/ Reformas-Estatuto-del-Personal-AcademicoUV-122019.pdf

Universidad Veracruzana. (2020). Historia. Desde 1944 hasta 1954. Recuperado de: https://www.uv.mx/universidad/1944-1954/
Valdés, M. C. (2008, julio-diciembre). Una invitación a pensar la Universidad Veracruzana. CPU-e, Revista de Investigación Educativa, 7. Recuperado de: https://www.uv.mx/cpue/num7/resena/valdes pensar uv.html

Vallaeys, François. (2014). La responsabilidad social universitaria: un nuevo modelo universitario contra la mercantilización. Revista Iberoamericana de Educación Superior. UNAM-México. Recuperado de: https://www.sciencedirect.com/science/articl e/pii/S2007287214719456 